\title{
Coat colour phenotype of Qingyu pig is associated with polymorphisms of melanocortin receptor 1 gene
}

\author{
Xiaoqian Wu ${ }^{1, a}$, Zhendong Tan ${ }^{1, a}$, Linyuan Shen ${ }^{1}$, Qiong Yang ${ }^{2}$, Xiao Cheng $^{1}$, Kun Liao ${ }^{3}$, Lin Bai ${ }^{1}$, \\ Surong Shuai ${ }^{1}$, Mingzhou Li ${ }^{1}$, Xuewei $\mathrm{Li}^{1}$, Shunhua Zhang ${ }^{1, *}$, and Li Zhu ${ }^{1, *}$
}

\begin{abstract}
* Corresponding Authors: Shunhua Zhang Tel: +86-2886291010, Fax: +86-2886291010, E-mail: zhangsh1919@163.com Li Zhu

Tel: +86-2886291010, Fax: +86-2886291010, E-mail: zhuli7508@163.com
\end{abstract}

${ }^{1}$ College of Animal Science and Technology, Sichuan Agricultural University, Chengdu 611130, China 2 Department of Animal Husbandry and Veterinary Medicine, Chengdu Agricultural College, Chengdu 611130, China

3 Pasturage Station of Tongjiang Agriculture Bbureau, Tongjiang, 636718, China

a These authors contributed equally to this work. Submitted May 11, 2016; Revised Aug 10, 2016; Accepted Dec 10, 2016
Objective: Qingyu pig, a Chinese indigenous pig breed, exhibits two types of coat colour phenotypes, including pure black and white with black spotting respectively. Melanocortin receptor 1 $(M C 1 R)$ and agouti signaling protein $(A S I P)$ are two widely reported pivotal genes that significantly affect the regulation of coat colour. The objectives of this study were to investigate whether the polymorphisms of these two genes are associated with coat colour and analyze the molecular mechanism of the coat colour separation in Qingyu pig.

Methods: We studied the phenotype segregation and used polymerase chain reaction amplification and Sanger sequencing to investigate the polymorphism of MC1R and ASIP in 121 Qingyu pigs, consisting of 115 black and 6 white with black spotted pigs.

Results: Coat colour of Qingyu pig is associated with the polymorphisms of MC1R but not $A S I P$. We only found 2 haplotypes, $E^{Q Y}$ and $E^{q y}$, based on the 13 observed mutations from $M C 1 R$ gene. Among which, $E^{q y}$ presented a recessive inheritance mode in black spotted Qingyu pigs. Further analysis revealed a g.462-463CC insertion that caused a frameshift mutation and a premature stop codon, thus changed the first transmembrane domain completely and lost the remaining six transmembrane domains. Altogether, our results strongly support that the variety of Qingyu pig's coat colour is related to MC1R.

Conclusion: Our findings indicated that black coat colour in Qingyu pig was dominant to white with black spotted phenotype and MC1R gene polymorphism was associated with coat colour separation in Qingyu pig.

Keywords: Qingyu Pig; Coat Colour; Melanocortin Receptor 1 (MC1R); Agouti Signaling Protein (ASIP); Polymorphism

\section{INTRODUCTION}

Coat colour phenotype is one of the most obvious morphological traits in animals that is linked with concealment, communication, and regulation of physiological processes [1]. In pigs, there are several varieties of coat colours including solid black (Large Black and Laiwu), solid white (LargeWhite and Landrace), red (Duroc) and brown (Dahe), belted (Hampshire), and spotted (Pietrain and Rongchang), etc.

Hitherto, more than 350 genes are reported to be involved in pigmentation, such as tyrosinaserelated protein 1 (TYRP1), KIT ligand (KITLG), and OCA2 melanosomal transmembrane protein (OCA2) that can directly or indirectly affect the production or regulation of two pigments pheomelanin (yellow to reddish brown) and eumelanin (black to brown) in mammals [2]. These two melanins are produced by melanocytes resident in skin and the proportions of which result in different coat colour [3]. Melanocortin receptor $1(M C 1 R)$ and its peptide antagonist agouti signaling protein $(A S I P)$ are two major genetic determinants of pigment phenotype in mammals $[1,4,5]$. When a-melanocyte-stimulating hormone (a-MSH) binds to MC1R, MC1R signaling 
is activated, eumelanin synthesis is induced, and dark colours are produced; otherwise, pheomelanin is generated alone and lighter colours are produced in the absence of MC1R signaling [6]. To date, mutations in $M C 1 R$ related to coat colour have been documented in a number of domestic mammals [7-9]. ASIP, a high-affinity antagonist of MC1R by nullifying the action of melanotropin alpha (a-MSH) [10], can influence MC1R signaling to determine coat colour in mammals, such as donkey [11], sheep [12], and dog [13].

Qingyu pig is a famous indigenous pig breed in China, which mainly lives in the mountainous areas of Sichuan province. This breed is characterized by its solid black coat colour, however, there are also some Qingyu pigs with white with black spotting. Up to now, many researches on coat colour variety of Chinese indigenous pigs have been performed [14-16], but there are no studies on the coat colour separation of Qingyu pig. To explore how the white with black spotted coat colour was formed in Qingyu pig, we documented and analyzed the phenotypes of this pig breed, investigated the variability of $M C 1 R, A S I P$, and analyzed their possible association with the white with black spotting coat colour.

\section{MATERIALS AND METHODS}

\section{Animals and sampling}

All experimental procedures involving animals were approved by the Animal Care and Use Committee of College of Animal Science and Technology, Sichuan Agricultural University, and were carried out in accordance with the National Research Council's Guide for the Care and Use of Laboratory Animals.

Qingyu pigs we studied were from a Qingyu pig nucleus farm in Bazhong County, Sichuan Province, China. The phenotypes of 121 piglets were collected. These piglets were from mating of 7 black boars with 10 black sows. Ear tissues of all these piglets were sampled in this study. The 121 ear samples were prepared and preserved in $75 \%$ ethanol at $-20^{\circ} \mathrm{C}$. Genomic DNA was extracted from ear samples with the Tiangen Genomic DNA Kit (Beijing, China).

\section{Polymerase chain reaction amplification and Sanger sequencing}

To detect the potential mutations in the exons along with partial region sequences, primer pairs were designed by the program Primer 5.0 based on the published sequences of Sus scrofa $M C 1 R$ (AF326520) and ASIP (AJ427478), respectively (Table 1, Figure $2 \mathrm{~A}, 2 \mathrm{~B}$ ). The $25 \mu \mathrm{L}$ polymerase chain reaction (PCR) reaction system contained $2 \mu \mathrm{L}$ DNA (approximately $25 \mathrm{ng} / \mu \mathrm{L}$ ), $1 \mu \mathrm{L} 10$ $\mathrm{pmol} / \mathrm{L}$ forward primer, $1 \mu \mathrm{L} 10 \mathrm{pmol} / \mathrm{L}$ reverse primer, $12.5 \mu \mathrm{L}$ $2 \times$ Taq PCR Mastermix (TIANGEN BIOTECH, Beijing, China) and $8.5 \mu \mathrm{L} \mathrm{ddH}_{2} \mathrm{O}$ (double-distilled water). PCR amplifications were performed on a PTC-200 Programmable Thermal Controller (M) Research Inc., Waltham, MA, USA) by the following steps: $95^{\circ} \mathrm{C}$ for $3 \mathrm{~min}, 35$ cycles of amplification including $30 \mathrm{~s}$ at $95^{\circ} \mathrm{C}$,
Table 1. PCR primers and conditions used for detecting mutations of $M C 1 R$ and ASIP

\begin{tabular}{|c|c|c|c|c|}
\hline $\begin{array}{l}\text { Primer } \\
\text { name }\end{array}$ & Primer sequence & $\begin{array}{c}\text { Primer } \\
\text { binding } \\
\text { region }\end{array}$ & $\begin{array}{l}\text { Size } \\
\text { (bp) }\end{array}$ & $\mathrm{T}_{\mathrm{m}}\left({ }^{\circ} \mathrm{C}\right)$ \\
\hline MC1R-1F & GCTGAGCACAGGCGAGGTTG & 5'UTR & 885 & 62 \\
\hline MC1R-1R & AGGAAGCAGAGGCTGGACAC & Exon1 & & \\
\hline$M C 1 R-2 F$ & CGCCAAGAACCGCAACCTG & Exon1 & 901 & 62 \\
\hline$M C 1 R-2 R$ & GTCCAGCGTCCATACCTTCAG & 3'UTR & & \\
\hline ASIP-1F & GTAGCAGTCGGAGCTGAAATC & Intron1 & 409 & 58 \\
\hline ASIP-1R & CGAATGTTCTTCTCACCTTGC & Intron2 & & \\
\hline ASIP-2F & CGCCTTCTTAGATTTCCCCTTTG & Intron2 & 437 & 58 \\
\hline ASIP-2R & CGCCAGGAAGTTTTTTGGTAGC & Intron3 & & \\
\hline ASIP-3F & ACAGGCAGAGGTGAGGAAGAGTG & Intron3 & 702 & 57 \\
\hline ASIP-3R & GGAAAGGGTGAAAGGCTGAATG & 3'UTR & & \\
\hline
\end{tabular}

$P C R$, polymerase chain reaction; $M C 1 R$, melanocortin receptor $1 ; A S I P$, agouti signaling protein.

annealing at the $\mathrm{Tm}$ (Table 1) for $30 \mathrm{~s}$ and $1 \mathrm{~min}$ at $72^{\circ} \mathrm{C}$, and finally $72^{\circ} \mathrm{C}$ for $5 \mathrm{~min}$. The products were detected by electrophoresis on $1.5 \%$ agarose gel, ethidium bromide stained and then purified. The qualified PCR products were directly sequenced by an ABI 3730XL DNA analyzer (Applied Biosystems, Carlsbad, CA, USA) using the BigDye Direct Cycle Sequencing Kit.

\section{Data analysis}

Nucleic acid and protein database searching were performed using BLAST at NCBI. DNA sequence data were analyzed by DNASTAR 7.1 software. Haplotype combinations of $M C 1 R$ were constructed with PHASE 2.1.1 software [17]. TMpred was utilized to predict the protein domains of MC1R. Phenotypes separation analysis, the frequencies of $M C 1 R$ allele and genotype, and chi square test of the association between phenotypes and genotypes were performed using SAS Software (version 9.2, USA).

\section{RESULTS AND DISCUSSION}

\section{Phenotypes separation of Qingyu pig}

Phenotypes separation analysis can define the inheritance of the main coat colour phenotypes [18]. In the nucleus farm of Qingyu pig, all boars and sows are solid black coat colour, while there are black and white with black spotting pigs in the descendants (Figure 1). The same coat colour polymorphism had been documented in Banna Mini-pig [19]. Among all the pigs in the farm, we found the phenotype of white with black spotted just existed in pigs from two litters (Table 2), and offspring from other litters were all black phenotype. According to the phenotypes distribution of Qingyu pig, we can determine that the black phenotype was completely dominant over white with black spotted coat colour and infer that the inheritance of Qingyu pigs' coat colour may result from a single gene segregation.

Mutations of ASIP in Qingyu pig 


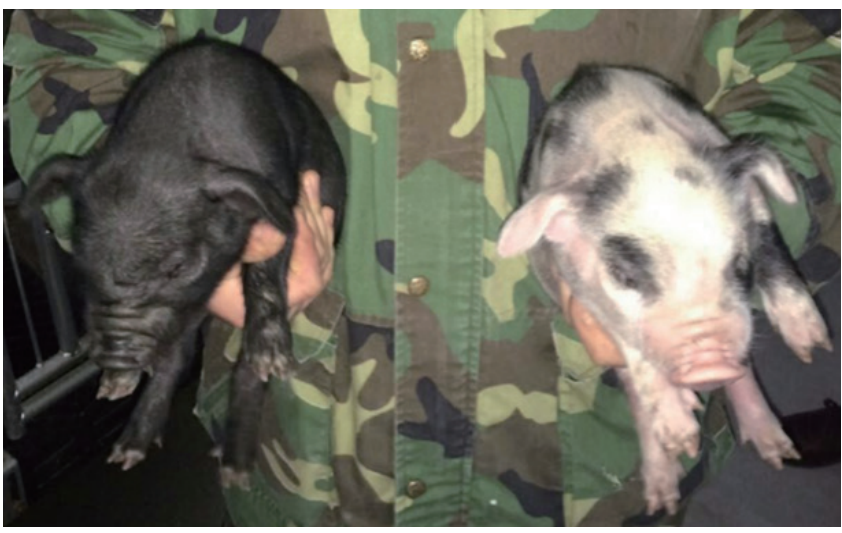

Figure 1. The phenotypes of white with black spotted (right) and solid black (left) Qingyu pigs.

ASIP was documented as an important gene associated with coat colour [20]. Sus scrofa ASIP, including three exons, two introns and parts of the 5'UTR and 3'UTR, was established (Figure 2A). Primers were set to amplify these three agouti exons, as well as parts of the intronic flanking regions to identify the mutations of ASIP. Six SNPs, two in introns ( $g .379 G>A$ and $g .5250 G>A$ ) and four in exons ( $g .133 A>G, g .257 G>A, g .5003 G>A$, and $g .5049 C>T)$, were detected in Qingyu pigs (Figure 2A). Among all these mutations, only one nucleotide substitution g.257G $>A$ (p.V53M) in coding sequence altered the encoded amino acid. Herein, the Met53 allele was found in both solid black and white with black
Table 2. Phenotypes separation in Qingyu pig

\begin{tabular}{|c|c|c|c|c|c|c|}
\hline \multirow{3}{*}{ Boar $^{1)}$} & \multirow{3}{*}{ Sow $^{1)}$} & \multicolumn{5}{|c|}{ Offspring } \\
\hline & & \multirow{2}{*}{$\mathbf{n}$} & \multicolumn{2}{|c|}{ Black } & \multicolumn{2}{|c|}{ White with black spotting } \\
\hline & & & 우 & $\hat{\sigma}$ & q & $\hat{\sigma}$ \\
\hline 114 & 170 & 10 & 3 & 5 & 2 & 0 \\
\hline 87 & 192 & 13 & 6 & 3 & 1 & 3 \\
\hline Totel & & 23 & 9 & 8 & 3 & 3 \\
\hline
\end{tabular}

${ }^{1)}$ Number of the boars and sows indicated the ID of the pigs.

spotted Qingyu pigs, which had also been documented in brownish red, blond and black Chinese indigenous breeds [16,21]. Apparently, we can exclude the $g .257 G>A$ mutation as a causative mutation for the coat colour variety of Qingyu pig. Though no mutations changed the function of ASIP protein, it is worthwhile to further analyse the regulatory region of ASIP gene, since a regulatory mutation in $A S I P$ has been documented to affect the phenotype in mammals [22,23].

\section{The correlation between polymorphisms of $M C 1 R$ and} coat colour separation in Qingyu pig

$M C 1 R$ is a critical gene known to be a major determinant of pig coat colour and is known for its role in regulating the change between eumelanin and pheomelanin biosynthesis pathways in mammals $[24,25]$. It has been documented that polymorphisms of $M C 1 R$ determined different coat colour in numerous studies $[26,27]$. Because $M C 1 R$ variant has been associated with the
A
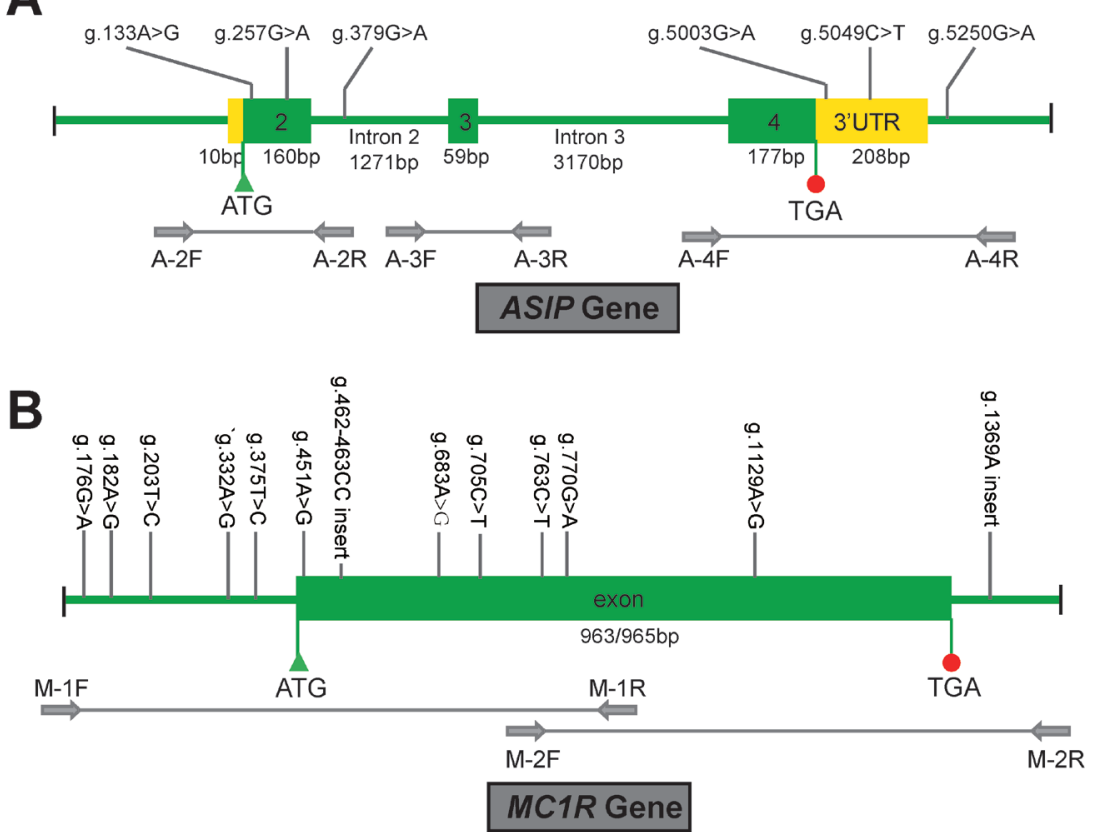

C

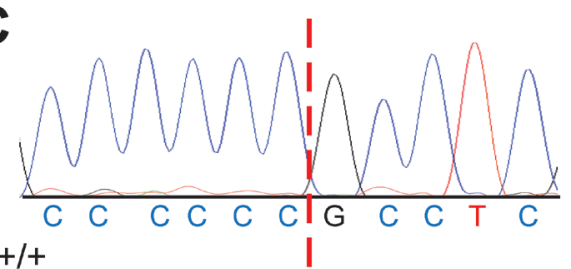
$+/+$
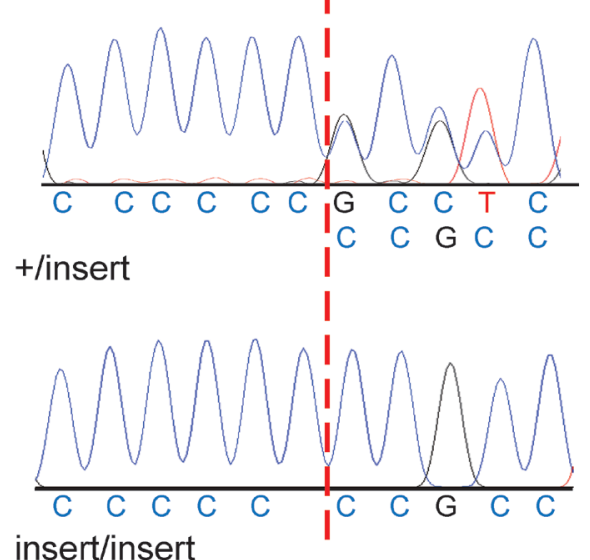

insert/insert

Figure 2. Mutations of $M C 1 R$ and ASIP in Qingyu pig. (A) The structure and mutations of MC1R in Qingyu pig. (B) The structure and polymorphisms of ASIP in Qingyu pig. (C) Sequencing results of each genotype at g.462-463CC insert locus of MC1R gene. Green boxes indicate protein coding sequences, while yellow boxes stand for $5^{\prime} U$ TR or $3^{\prime} U T R$. The start codon (ATG) and the stop codon (TGA) are indicated by the green triangle $(\boldsymbol{\Delta})$ and red circle $(\bullet)$ symbols, respectively. Numbers below the gene structure indicate the length of exons and introns in bp. MC1R, melanocortin receptor $1 ; A S I P$, agouti signaling protein. 
Table 3. Haplotypes and mutations in Qingyu pig

\begin{tabular}{|c|c|c|c|c|c|c|c|c|c|c|c|c|c|}
\hline \multirow{2}{*}{ Haplotype } & \multicolumn{13}{|c|}{ Alleles } \\
\hline & 176 & 182 & 203 & 332 & 375 & 451 & $462-463$ & $683 / 685$ & 705/707 & $763 / 765$ & 770/772 & $1129 / 1131$ & $1369 / 1371$ \\
\hline$\overline{E^{Q Y}}$ & G & A & $T$ & A & $\mathrm{T}$ & A & - & A & $C$ & C & $G$ & A & - \\
\hline$E^{\text {qy }}$ & A & G & C & G & C & G & $\mathrm{CC}$ & G & $\mathrm{T}$ & $\mathrm{T}$ & A & G & A \\
\hline
\end{tabular}

Table 4. The distribution of MC1R haplotypes and genotypes in Qingyu pig

\begin{tabular}{|c|c|c|c|c|c|c|c|}
\hline \multirow{2}{*}{ Phenotype } & \multirow{2}{*}{$\mathrm{n}$} & \multicolumn{2}{|c|}{ Haplotype frequency ${ }^{1)}$} & \multicolumn{3}{|c|}{ Genotype (No./freq) } & \multirow{2}{*}{$x^{2}$} \\
\hline & & $E^{Q Y}(\%)$ & $E^{\mathrm{qy}}(\%)$ & $E^{Q Y} E^{Q Y}(\%)$ & $E^{\mathrm{QY}} E^{\mathrm{qy}}(\%)$ & $E^{\text {qy }} E^{\text {qy }}(\%)$ & \\
\hline White with black spotting & 6 & 0 & 100 & $0 / 0$ & $0 / 0$ & $6 / 100$ & $121^{* *}$ \\
\hline Black & 115 & 83.48 & 16.52 & $77 / 66.96$ & $38 / 33.04$ & $0 / 0$ & \\
\hline
\end{tabular}

$M C 1 R$, melanocortin receptor 1 .

$x^{2}$ : Chi square value, $\mathrm{df}=2, x^{2}=5.99, \mathrm{p}=0.05, x^{2}=9.21, \mathrm{p}=0.01 .{ }^{* *}$ Meant the extremely significant level.

1) The haplotype $E^{\text {qy }}$ owned $g .462-463 C C$ insert but $E^{\text {QY }}$ did not.

Japanese brindling coat colour in rabbits [28], we sequenced the exon along with flanking regions of $M C 1 R$ gene of these two litters to elucidate the genetic mechanisms behind coat colour separation of Qingyu pig. A total of 13 mutations have been detected (Figure 2B). We observed 7 nucleotide substitutions (g.451A>G, g.462-463CC insertion, g.683A $>$ G, g.705C > T, g.763C $>T, g .770 G>A, g .1129 A>G)$ occurred in the coding region and 6 polymorphisms ( $g .176 G>A, g .182 A>G, g .203 T>C, g .332 A>G$, g.375T $>C, g .1369 A$ insertion) were distributed in the flanking regions. We analyzed the haplotypes of $M C 1 R$ utilizing the polymorphisms both in exon and introns, and found two longer haplotypes, $E^{Q Y}$ and $E^{q y}$, from these 13 closely linked mutations (Table 3). To further determine the haplotypes, we sequenced MC1R of 98 solid black Qingyu pigs from another 8 litters and the same mutations and haplotypes were detected. Then, we analyzed the $M C 1 R$ genotypes of all these 121 Qingyu pigs. The distribution of $M C 1 R$ genotypes was significantly different between black and spotted Qingyu pigs $(\mathrm{p}<0.01)$. All the 6 white with black spotted Qingyu pigs were $E^{q y} E^{q y}$ genotypes with no $E^{Q Y}$ haplotype, while $E^{Q Y}$ occurred in all the 115 black pigs (Table 4). Hence, we inferred that the phenotype separation of Qingyu pig was associated with $M C 1 R$ gene and $E^{q y}$ presented a recessive inheritance mode in black spotted Qingyu pigs. Interestingly, we found that the g.451A>G mutation was a synonymous mutation whereas g.462-463CC insertion caused a frameshift mutation which both changed the amino acids after 23rd codon and generated a premature stop codon at position 56 (Figure 2C, Figure 3). MC1R, a known major determinant of pigment phenotype, is

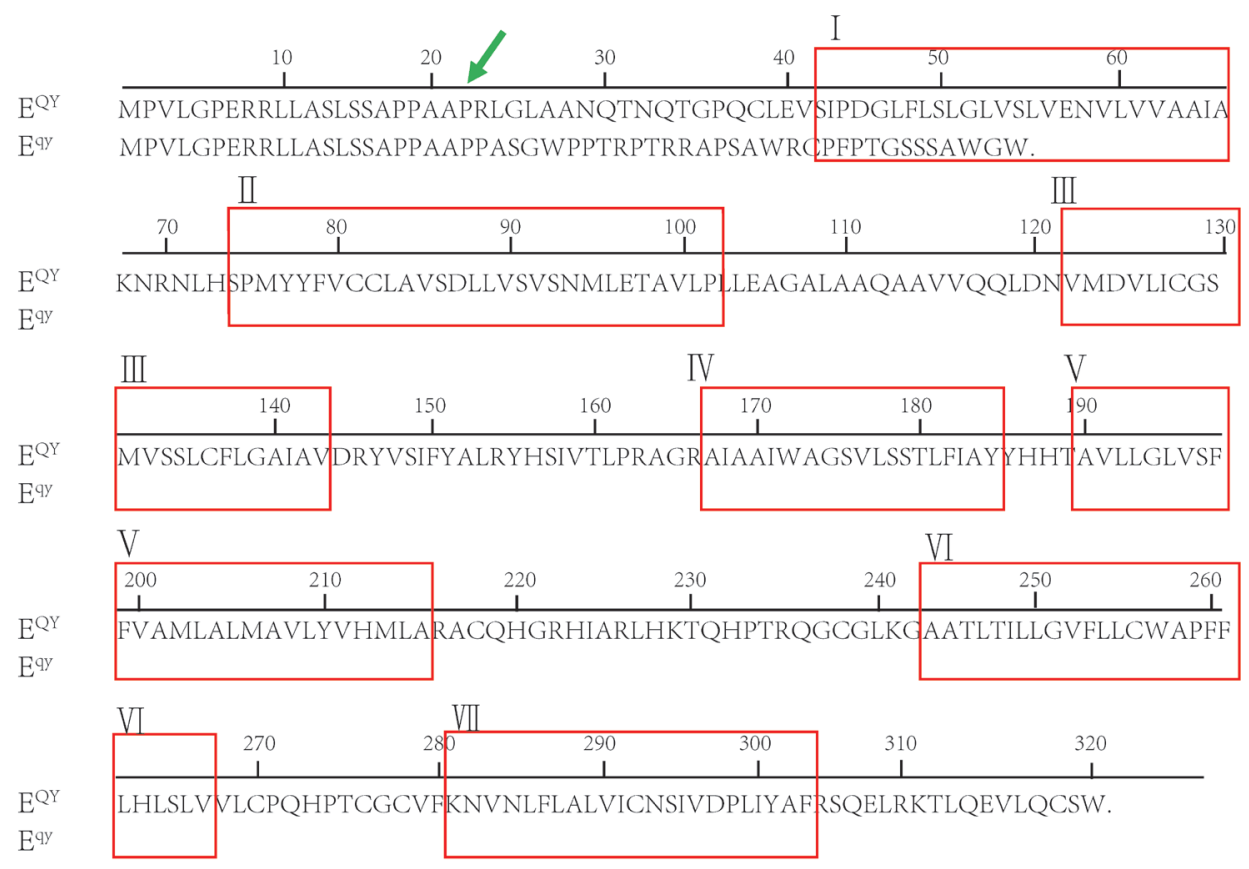

Figure 3. Amino acid sequence alignment of $M C 1 R$ variants in Qingyu pig. The seven transmembrane domains are indicated in boxes and denoted with roman numerals. The arrow is used to sign the beginning of amino acid changes. MC1R, melanocortin receptor 1. 
a seven-transmembrane G-protein-coupled protein [29]. Further analysis revealed that the insertion mutation caused a complete change of the first transmembrane domain, and deletion of the remaining six transmembrane domains (Figure 3 ). The $C C$ insertion was supposed to produce a red pigmentation caused by the complete loss of MC1R signaling. However, the observed phenotypes of the $C C$ insertion mutation were highly diverse and the coat colour can range from white, red with black spotted, white with black spotted to almost solid black [25,30,31]. It has been documented that the $C C$ insertion was unstable in organisms and the somatic reversion events restored the frame and function of MC1R, resulted in black spotted [32]. Since there was no evidence to explain the formation of the white background of coat colour, we can just infer that it may be produced by the absence of melanocytes or modified by other genes [33]. In general, the coat colour segregation of Qingyu pigs is related to $M C 1 R$.

\section{CONCLUSION}

$M C 1 R$ gene played a significant role in regulation of coat colour variety. Meanwhile, not only gene verification but also phenotype separation suggested that the white with black spotted phenotype was recessive to black coat colour in Qingyu pig. Mutations were detected both in exon and introns of MC1R gene, and we found 2 haplotypes, $E^{Q Y}$ and $E^{a y}$, from 13 closely linked mutations of $M C 1 R$. Moreover, the mutations in $M C 1 R$ can be used as diagnostic makers for Qingyu pig breeding to clear the coat colour of white with black spotting. In summary, the study advanced our understanding of the molecular basis of coat colour variation in Qingyu pig.

\section{CONFLICT OF INTEREST}

We certify that there is no conflict of interest with any financial organization regarding the material discussed in the manuscript.

\section{ACKNOWLEDGMENTS}

The study was supported by the Chinese National Spark Program (No. 2015GA810001), the Chinese National Sci \& Tech Support Program (No. 2015BAD03B01-11), the Program for Changjiang Scholars and Innovative Research Team in University (No. IRT 13083), and the earmarked fund for China Agriculture Research System (No. CARS-36-05B).

\section{REFERENCES}

1.Andersson L. Genetic dissection of phenotypic diversity in farm animals. Nat Rev Genet 2001;2:130-8.

2.Chandramohan B, Renieri C, La Manna V, La Terza A. The alpaca agouti gene: genomic locus, transcripts and causative mutations of eumelanic and pheomelanic coat color. Gene 2013;521:303-10.
3.Ito S, Wakamatsu K. Chemistry of mixed melanogenesis-pivotal roles of dopaquinone. Photochem Photobiol 2008;84:582-92.

4.Bonilla C, Boxill L-A, Mc Donald SA, et al. The $8818 \mathrm{G}$ allele of the agouti signaling protein (ASIP) gene is ancestral and is associated with darker skin color in African Americans. Hum Genet 2005;116:402-6.

5.Norris BJ, Whan VA. A gene duplication affecting expression of the ovine ASIP gene is responsible for white and black sheep. Genome Res 2008;18:1282-93.

6.Dun G, Li X, Cao H, Zhou R, Li L. Variations of melanocortin receptor 1 (MC1R) gene in three pig breeds. J Genet Genomics 2007;34:777-82.

7.Canu A, Vilaça S, Iacolina L, et al. Lack of polymorphism at MC1R wild-type allele and evidence of domestic allele introgression across European wild boar populations. Mamm Biol-Zeitschrift für Säugetierkunde 2016;81:477-9.

8.Cieslak J, Cholewinski G, Mackowski M. Genotyping of coat color genes (MC1R, ASIP, PMEL17 and MATP) polymorphisms in coldblooded horses bred in Poland reveals sporadic mistakes in phenotypic descriptions. Anim Sci Pap Rep 2013;31.

9.Wang G-d, Cheng L-g, Fan R-x, et al. Signature of balancing selection at the MC1R gene in Kunming dog populations. PloS one 2013;8: e55469.

10. Lamoreux ML, Delmas V, Larue L, Bennett DC. Pigment-type switching. The Colors of Mice: A Model Genetic Network. Oxford, UK: Wiley-Blackwell; 2010. pp. 177-206.

11. Abitbol M, Legrand R, Tiret L. A missense mutation in the agouti signaling protein gene $(A S I P)$ is associated with the no light points coat phenotype in donkeys. Genet Sel Evol 2015;47:28.

12. Han J, Yang M, Yue Y, et al. Analysis of agouti signaling protein (ASIP) gene polymorphisms and association with coat color in Tibetan sheep (Ovis aries). Genet Mol Res 2015;14:1.

13. Li Y, Si S, Guo P, Li L, Bai C, Yan S. Cloning and identification of the ASIP gene in Chinese raccoon dog (Nyctereutes procyonoides procyonoides). Genet Mol Res 2014;14:16312-6.

14. Lai F, Ren J, Ai H, et al. Chinese white Rongchang pig does not have the dominant white allele of KIT but has the dominant black allele of MC1R. J Hered 2007;98:84-7.

15. Ren J, Mao H, Zhang Z, et al. A 6-bp deletion in the TYRP1 gene causes the brown colouration phenotype in Chinese indigenous pigs. Heredity 2011;106:862-8.

16. Wu X, Zhang Y, Shen L, et al. A 6-bp deletion in exon 8 and two mutations in introns of TYRP1 are associated with blond coat color in Liangshan pigs. Gene 2016;578:132-6.

17. Stephens M, Smith NJ, Donnelly P. A new statistical method for haplotype reconstruction from population data. Am J Hum Genet 2001;68: 978-89.

18. Valbonesi A, Apaza N, La Manna V, et al. Inheritance of white, black and brown coat colours in alpaca (Vicuna pacos L.). Small Rumin Res 2011;99:16-9.

19. Jinlong $H$, Hailong $H$, Pei W, Yangzhi Z, Heng X. The association of $M C 1 R$ gene with coat color of Banna mini-pig inbred line (BMI). J Anim Vet Adv 2012;11:503-8.

20. Fontanesi L, Beretti F, Riggio V, et al. Copy number variation and 
missense mutations of the agouti signaling protein (ASIP) gene in goat breeds with different coat colors. Cytogenet Genome Res 2009; 126:333-47.

21. Mao H, Ren J, Ding N, Xiao S, Huang L. Genetic variation within coat color genes of MC1R and ASIP in Chinese brownish red Tibetan pigs. Anim Sci J 2010;81:630-4.

22. Drögemüller C, Giese A, Martins-Wess F, et al. The mutation causing the black-and-tan pigmentation phenotype of Mangalitza pigs maps to the porcine ASIP locus but does not affect its coding sequence. Mamm Genome 2006;17:58-66.

23. Pielberg GR, Golovko A, Sundström E, et al. A cis-acting regulatory mutation causes premature hair graying and susceptibility to melanoma in the horse. Nat Ggenet 2008;40:1004-9.

24. Deng S, Gao J, Ren J, et al. Studies of the relationship of melanocortin receptor $1(M C 1 R)$ gene with coat color phenotype in pigs. Acta Genet Sin 2003;30:949-54.

25. Kijas J, Wales R, Törnsten A, et al. Melanocortin receptor 1 (MC1R) mutations and coat color in pigs. Genetics 1998;150:1177-85.

26. Kim S-H, Jung K, Lee H, et al. Effects of genotype mutation and coat color phenotype on the offspring from mating system of MC1R genotype patterns in Korean Brindle Cattle. J Embryo Transf 2013;28: $215-22$
27. Våge DI, Nieminen M, Anderson DG, Røed KH. Two missense mutations in melanocortin 1 receptor (MC1R) are strongly associated with dark ventral coat color in reindeer (Rangifer tarandus). Anim Genet 2014;45:750-3.

28. Fontanesi L, Scotti E, Colombo M, et al. A composite six bp in-frame deletion in the melanocortin 1 receptor $(M C 1 R)$ gene is associated with the Japanese brindling coat colour in rabbits (Oryctolagus cuniculus). BMC Genet 2010;11:59.

29. Zhang Y, Li Q, Ye S, et al. New variants in the melanocortin 1 receptor gene (MC1R) in Asian cattle. Anim Genet 2014;45:609-10.

30. Klungland H, Vage D, Gomez-Raya L, Adalsteinsson S, Lien S. The role of melanocyte-stimulating hormone (MSH) receptor in bovine coat color determination. Mamm Genome 1995;6:636-9.

31. Robbins LS, Nadeau JH, Johnson KR, et al. Pigmentation phenotypes of variant extension locus alleles result from point mutations that alter MSH receptor function. Cell 1993;72:827-34.

32. Kijas J, Moller M, Plastow G, Andersson L. A frameshift mutation in MC1R and a high frequency of somatic reversions cause black spotting in pigs. Genetics 2001;158:779-85.

33. Pavan WJ, Mac S, Cheng M, Tilghman SM. Quantitative trait loci that modify the severity of spotting in piebald mice. Genome Res 1995; 5:29-41. 